\title{
Review
}

\section{KCNQ potassium channels in sensory system and neural circuits}

\author{
Jing-jing WANG, Yang LI*
}

Key Laboratory of Receptor Research, Shanghai Institute of Materia Medical, Chinese Academy of Sciences, Shanghai 201203, China

\begin{abstract}
$\mathrm{M}$ channels, an important regulator of neural excitability, are composed of four subunits of the Kv7 (KCNQ) $\mathrm{K}^{+}$channel family. M channels were named as such because their activity was suppressed by stimulation of muscarinic acetylcholine receptors. These channels are of particular interest because they are activated at the subthreshold membrane potentials. Furthermore, neural KCNQ channels are drug targets for the treatments of epilepsy and a variety of neurological disorders, including chronic and neuropathic pain, deafness, and mental illness. This review will update readers on the roles of KCNQ channels in the sensory system and neural circuits as well as discuss their respective mechanisms and the implications for physiology and medicine. We will also consider future perspectives and the development of additional pharmacological models, such as seizure, stroke, pain and mental illness, which work in combination with drug-design targeting of KCNQ channels. These models will hopefully deepen our understanding of KCNQ channels and provide general therapeutic prospects of related channelopathies.
\end{abstract}

Keywords: KCNQ channels; M channels; neural circuits; channelopathy; epilepsy; neuropathic pain; deafness; mental illness

Acta Pharmacologica Sinica (2016) 37: 25-33; doi: 10.1038/aps.2015.131; published online 21 Dec 2015

\section{Introduction}

More than 70 potassium channel genes have been found in human, and some of them have been shown to be associated with diseases. One of the first neurotransmitter-regulated channels to be identified, some 35 years ago, was the $\mathrm{M}$ channel. $\mathrm{M}$ channels are low-threshold $\mathrm{K}^{+}$channels that were originally identified in the early 1980s in frog ${ }^{[1]}$ and rat sympathetic neurons. They were named as such because their activity was inhibited through stimulation of muscarinic acetylcholine receptors $(\mathrm{mAChR})^{[2]}$. This time- and voltage-dependent current regulates the firing rate of excitable cells after exposure to an excitatory stimulus. $\mathrm{M}$ channels are now known to be composed of subunits of the KCNQ (Kv7) $\mathrm{K}^{+}$channel family. These channels are of particular interest in that they are activated by membrane potentials that are more negative than the action-potential threshold. Furthermore, neural KCNQ channels are drug targets for epilepsy treatments and are potential therapeutics that are used to treat a variety of neural disorders, including chronic and neuropathic pain, deafness, and mental illness.

Typically KCNQ channels consist of four subunits that encircle a central pore, which enables the selective passage of

\footnotetext{
* To whom correspondence should be addressed. E-mail liyang@simm.ac.cn

Received 2015-09-15 Accepted 2015-11-10
}

potassium ions across the cell membrane. Each subunit consists of six transmembrane segments (S1-S6) with both $\mathrm{N}$ - and C-termini on the intracellular side of the membrane. The S4 segment contains the voltage-sensor of the channel; and the S5 and S6 segments, along with an intervening re-entrant loop (P-loop domain), form the pore region. Four P-loops combine to form the selectivity filter of the channel. All KCNQ channel members have a large C-termini which may form 'receptorsomes' or 'channelosomes' ${ }^{[2]}$ for incorporation with multiple signaling pathways.

\section{Distribution and function of KCNQ channels}

KCNQ genes encode a growing family of six trans-membrane domains, which are single pore-loop, $\mathrm{K}^{+}$channel a-subunits that have a wide range of physiological correlates. KCNQ1 (KvLTQ1) is co-assembled with the product of the KCNE1 (minimal $\mathrm{K}^{+}$-channel protein) gene in the heart to form a cardiac-delayed rectifier-like $\mathrm{K}^{+}$current. Mutations in this channel can cause one form of inherited long QT syndrome (LQT1) ${ }^{[3]}$ as well as be associated with a form of deafness, thereby indicating that KCNQ1 has a role in $\mathrm{K}^{+}$recycling in the inner ear ${ }^{[4]}$. KCNQ1 can also co-assemble with KCNE3, and may be the molecular correlate of the cyclic AMP-regulated $\mathrm{K}^{+}$current that is present in colonic crypt cells. KCNQ2 and KCNQ3 have $40 \%$ homology with KCNQ1, and KCNQ2 and KCNQ3 heteromultimers are thought to underlie the $\mathrm{M}$-current ${ }^{[5]}$; mutations 
in these genes may cause benign familial neonatal convulsions (BFNC), a rare form of neonatal epilepsy in humans ${ }^{[4,6,7]}$. The KCNQ4 gene is thought to encode the molecular correlate of $I_{\mathrm{K}, \mathrm{n}}$ in outer hair cells (OHCs) of the cochlea and $I_{\mathrm{K}, \mathrm{L}}$ in Type I hair cells of the vestibular apparatus ${ }^{[4]}$, mutations that lead to a form of inherited deafness. The expression of KCNQ4 in the CNS is restricted to certain structures in the brainstem, most notably to nuclei and tracts of the central auditory pathway and to trigeminal ganglia ${ }^{[8]}$. The recently identified KCNQ4, which is also present in sensory neurons of the DRG as well as in the peripheral lanceolate endings and circular nerve fibers of hair follicles and in Meissner bodies, can modulate stimulus-excitation coupling ${ }^{[9]}$. The KCNQ5 gene was identified in 2000, and is expressed in brain and skeletal muscle. Mutations in these genes may cause retinopathy ${ }^{[4,10]}$. KCNQ5 can coassemble with KCNQ3, which suggests that it may also have a role in M-current heterogeneity ${ }^{[11]}$. Using pre- and postsynaptic recordings combined with immunohistochemistry, KCNQ5 channels with unusually negative activation voltage were observed to be expressed in the calyx of Held, which is the presynaptic neuron of the medial nucleus of the trapezoid body $(\mathrm{MNTB})^{[12]}$. Moreover, immunocytochemistry analysis shows that KCNQ2/3 and KCNQ5 are expressed in DRG neurons ${ }^{[13]}$, where they might modulate pain sensitivity.

\section{The gating of KCNQ channels}

Neural KCNQ channels control somatic excitability, bursting and neurotransmitter release throughout the nervous system. Their activity is regulated by multiple signaling pathways. In superior cervical ganglion sympathetic neurons, muscarinic $\mathrm{M} 1$, angiotensin II $\mathrm{AT}_{1}$, bradykinin $\mathrm{B}_{2}$ and purinergic P2Y agonists suppress the $\mathrm{M}$ current $\left(\mathrm{I}_{\mathrm{M}}\right)$. Probes of PLC activity show that agonists of all four receptors are able to induce robust phosphatidylinositol 4,5-bisphosphate $\left(\mathrm{PIP}_{2}\right)$ hydrolysis ${ }^{[14,15]}$. There are two basic types of $\mathrm{G}_{\mathrm{q} / 11}$-mediated signaling mechanisms in SCG neurons. The first mechanism involves the stimulation of $\mathrm{M}_{1} \mathrm{mACh}$ and angiotensin II AT1 receptors and the principally induced depletion of $\mathrm{PIP}_{2}{ }^{[16]}$. Perhaps due to the lack of spatial co-localization with inositol trisphosphate $\left(\mathrm{IP}_{3}\right)$ receptors, the stimulation of these receptors does not elicit $\left[\mathrm{Ca}^{2+}\right]_{\mathrm{i}}$ increases. Rather, membrane PIP $\mathrm{P}_{2}$ levels fall and the $\mathrm{M}$ channels are inhibited. The second mechanism is induced by bradykinin $\mathrm{B}_{2}$ and purinergic P2Y receptors and is based upon the $\mathrm{IP}_{3}$-mediated increase in intracellular $\mathrm{Ca}^{2+}$ that stimulate $\mathrm{PIP}_{2}$ synthesis, thereby preventing its depletion ${ }^{[17-19]}$, and subsequent $\mathrm{Ca}^{2+}$ binding to calmodulin (CaM), which acts upon the channels ${ }^{[19-21]}$. The $\mathrm{Ca}^{2+}{ }_{\mathrm{i}}$ signals that are produced by these receptors also augment PI4-kinase activity, thereby stabilizing $\mathrm{PIP}_{2}$ levels. $\mathrm{Ca}^{2+} / \mathrm{CaM}$ activity could involve the reduction of the channels' affinity for $\mathrm{PIP}_{2}$, which would then unbind from the channel proteins. Such competitive or allosteric regulation of the affinity of membrane transport proteins for regulatory $\mathrm{PIP}_{2}$ molecules as a mechanism for modulation is widespread, and may act as a coincidence-detector motif for spatiotemporal targeting of receptor stimulation of the proper ion channel targets within the cell ${ }^{[22-24]}$.
When compared with other Kv channels, KCNQ channels have an extended intracellular carboxyl terminus that seems to be the target of several modulatory signals. Examples of this include modulation by $\mathrm{Ca}^{2+}$, using calmodulin as a channel $\mathrm{Ca}^{2+}$ sensor ${ }^{[20,21,25]}$, and regulation by plasma membrane phosphoinositides $^{[14,21,26]}$, perhaps in concert with protein kinase $\mathrm{C}^{[27]}$. Furthermore, Src tyrosine kinase suppresses ${ }^{[28]}$, while the cysteine-modifying reagent N-ethylmaleimide (NEM) augments ${ }^{[29]}$, the currents of KCNQ channels in a subunit-specific manner. This provides insights into the molecular mechanisms that regulate the gating of KCNQ channels.

The regulatory function of $\mathrm{PIP}_{2}$ on KCNQ channels has been extensively investigated. Most recently, studies have indicated that there are multiple $\mathrm{PIP}_{2}$ binding sites that are located at lipid-protein surfaces that are formed by the $\mathrm{S6}$ segment, the S4-S5 linker, the S2-S3 linker, and the intracellular C-terminal of the KCNQ channel ${ }^{[30]}$. $\mathrm{PIP}_{2}$ could migrate between its binding sites, such as dynamic migration between the S4-S5 linker and S2-S3 linker, during the gating transitions between activation and de-activation ${ }^{[31]}$. As shown in Figure 1, Chen et al reported that there is extensive dynamic migration of $\mathrm{PIP}_{2}$ between the S4-S5 linker and the S2-S3 linker, which directly affects the rate of gating transition of the KCNQ2 channel. The

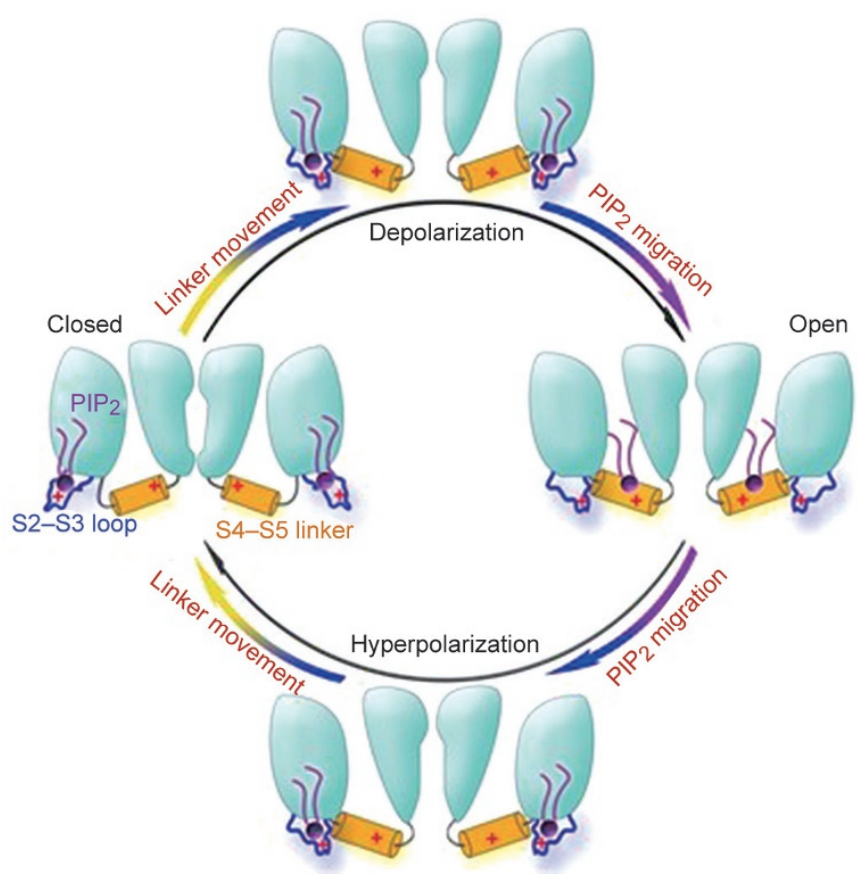

Figure 1. The hypothesized mechanism of $\mathrm{PIP}_{2}$ migration within the KCNQ2 channel. In the closed state, $\mathrm{PIP}_{2}$ molecules are bound to the S2-S3 loop of the KCNQ2 channel. Upon channel activation, the conformation of the S4-S5 linker is altered, thereby enabling the $\mathrm{PIP}_{2}$ molecules to migrate from the S2-S3 loop to the S4-S5 linker. The binding of $\mathrm{PIP}_{2}$ to the S4-S5 linker stabilizes the open conformation, which also means that $\mathrm{PIP}_{2}$ has to dissociate from the linker to close the channel. The migration of $\mathrm{PIP}_{2}$ from the S4-S5 linker to the S2-S3 loop facilitates $\mathrm{PIP}_{2}$ dissociation from the linker and therefore strongly influences the deactivation kinetics of the channel. 
recent discovery that A-kinase anchoring proteins (AKAPs) modulate voltage-gated neuronal M-type (KCNQ, Kv7) $\mathrm{K}^{+}$ channels highlights that AKAP79/150 has emerged as an integrative protein for diverse signals to achieve spatiotemporal resolution of directed cellular regulation. The highly dynamic feature of AKAP79/150 complexes include the dual fast and slow regulation of ion channels that alters $\mathrm{PIP}_{2}$ sensitivity and CaM interactions with KCNQ channels ${ }^{[32]}$, which indicates the close regulation of function between the membrane and physiological input.

\section{The role of KCNQ channels in neural circuits}

Action potential firing over a wide frequency range depends upon multiple small currents that flow at subthreshold voltages, which speed or retard the approach to the action potential threshold and thereby influence the spike rate and pattern of firing. Spike after-potentials (ie, after-hyperpolarizations (AHPs) and after-depolarizations (ADPs)) play an important role in shaping neuronal firing patterns ${ }^{[33-35]}$. The application of retigabine, a KCNQ channel modulator, completely abolished the bursts in an XE-991-sensitive manner. Furthermore, application of the KCNQ channel blockers linopirdine or XE-991 alone abolished the gamma frequency, but not the higher-frequency population spike firing that was observed during low $\mathrm{Ca}^{2+} /$ high $\mathrm{K}^{+}$bursts. These data suggest that KCNQ channels are likely to play a role in the regulation of synchronous population firing activity ${ }^{[36]}$.

These heterotetrameric KCNQ channels are thought to underlie the neuronal M-current, a non-inactivating, slowly deactivating, sub-threshold current that has long been known to exert a powerful stabilizing influence upon neuronal excitability $^{[37]}$. Small reductions in this current, either as a result of pharmacological inhibition, physiological modulation or mutation, can result in dramatic increases in neuronal excitability $^{[38]}$. Recent research supports this mechanism. The in vitro physiological characterization of PFC neurons in aged primates has indicated increases in the slow AHP, which is mediated in part by KCNQ channels ${ }^{[39]}$. In vivo 7-channel recording in the dorsolateral PFC found that pyramidal cells synapse on spines of neurons in aged monkeys, where elevated cyclic-AMP signaling reduces persistent firing by opening HCN- and KCNQ-potassium channels ${ }^{[12]}$, which effectively inhibits synaptic input and modulates the strength of network connections between pyramidal cells with similar spatial tuning that would otherwise excite each other to maintain persistent firing across the delay period ${ }^{[40]}$. At the same time, patching the calyx of Held, a giant glutamatergic terminal in the medial nucleus of the trapezoid body (MNTB) showed that KCNQ5 channels maintain a negative membrane potential, thus minimizing the substantial contributions from other outward currents and decreasing the probability of neurotransmitter release ${ }^{[11]}$. The other likely sources that contribute to the resting conductance of the terminal are the HCN channels ${ }^{[41,42]}$ and the persistent $\mathrm{Na}^{+}$current $(\mathrm{NaP})^{[43]}$. These three channels (KCNQ, HCN, and $\mathrm{NaP}$ ) together account for $98 \%$ of the resting conductance of the terminal. Electrophysiological recordings from single afferents in $\mathrm{kcnq}^{-/-}$mice and mice that carry a KCNQ4 mutation found that DFNA2-type monogenic dominant human hearing loss exhibited an elevated mechanosensitivity and altered frequency response that results in rapid adaptation. Human subjects from independent DFNA2 pedigrees outperformed age-matched control subjects when tested for vibrotactile acuity at low frequencies ${ }^{[9]}$. Increasingly, researchers are finding that KCNQ channels maintain the resting membrane potential and modulate the strength of the synapse.

In view of this central role of KCNQ channels in neural excitability, it is not surprising that some specific epilepsies are single-gene disorders that result from mutations in KCNQ channel genes ${ }^{[44]}$. For example, benign familial neonatal convulsion (BFNC) is an autosomal dominant idiopathic epilepsy that is characterized by unprovoked partial or generalized clonic convulsions that sometimes occur with ocular symptoms and apnoea ${ }^{[45]}$. BFNC was linked to two different loci (20q13.3 and 8q24) that are now known to encode the KCNQ2 and KCNQ3 potassium channel genes, respectively ${ }^{[6,7,46]}$. There are approximately ten known mutations in $\mathrm{KCNQ}^{[6,46]}$, but only two in $\mathrm{KCNQ}^{[47]}$. These mutations include MISSENSE, FRAME-SHIFT, and SPLICE-SITE mutations and, in one family, the KCNQ2 gene is deleted from one chromosome ${ }^{[46]}$. Currents from heteromeric KCNQ2/KCNQ3 channels were estimated to be reduced by only $25 \%$ in people who suffer from BFNC, which is sufficient to increase neuronal excitability to epileptogenic levels in early infancy ${ }^{[48]}$. This small safety margin may be related to the physiological importance of increases in neuronal excitability that result from the neurotransmitter-mediated inhibition of KCNQ2/KCNQ3. The high degree of sensitivity that is required for this modification of excitability also has the result that slightly greater inhibition can result in epilepsy. The homozygous deletion of KCNQ2 in mice results in death a few hours after birth because of the inability to breathe properly, while heterozygous animals develop normally and lack spontaneous epileptic activity, but are more susceptible to pentylenetetrazoleinduced seizures. For this reason, mice that are heterozygous $\left(\mathrm{kcnq}^{+/-}\right)$can serve as valuable models for studying the effects of KCNQ2-mediated reductions in currents.

\section{KCNQ channels in hearing}

Hearing impairment is a common sensory defect in humans. Non-syndromic hereditary forms in which the hearing loss is the only clinical sign have proven to be genetically heterogeneous. Two lines of evidence have implicated KCNQ1 in the function of the inner ear. First, mRNA for KCNQ1 and KCNE1 has been shown in the apical surface of marginal cells of the stria vascularis of the cochlea. Second, in the homozygous form of Jervell and Lange-Nielsen syndrome (JLNS), mutant KCNQ1 channels cause bilateral deafness. During auditory stimulation, $\mathrm{K}^{+}$moves from the endolymph into hair cells. $\mathrm{K}^{+}$then moves out of the basal portion of hair cells (possibly via KCNQ4-containing channels) into what is thought to be the cellular syncitium of supporting cells, which recycle 
the $\mathrm{K}^{+}$back into the endolymph via the stria vascularis. The $\mathrm{K}^{+}$channels on the marginal cells regulate the flux are thought to contain KCNQ1 and KCNE1 proteins. Any reduction in the concentration gradient of $\mathrm{K}^{+}$results in the reduction of endolymph potential, and this can reduce sensitivity to auditory stimuli. A similar event is also thought to occur in the marginal cells of the vestibular epithelium. Mutations in both KCNQ1 (JLNS1) and KCNE1 (JLNS2) can result in hearing loss and vestibular disturbance; however, the latter is less phenotypically obvious in humans because we adapt well to the loss of vestibular function. Both frameshift and missense mutation, which results in nonfunctional, dominant negative and impaired assembly channels, have been described ${ }^{[49-51]}$.

KCNQ4 could almost be described as a "hearing $\mathrm{K}^{+}$channel" because it is almost exclusively expressed in the inner ear, the vestibular apparatus, and a number of nuclei in the central auditory pathway ${ }^{[52]}$. All missense mutations and deletions that have been identified in KCNQ4 have been associated with DFNA2, a subtype of autosomal dominant non-syndromic sensorineural progressive hearing loss (ADNSHL) in which high frequencies are initially affected. This phenotype is consistent with the predominant pattern of KCNQ4 expression and native $\mathrm{K}^{+}$currents that are primarily mediated by homomeric KCNQ4 channels in the sensory outer hair cells (OHCs) of the basal turns of the cochlea ${ }^{[8,52,53]}$. Missense mutations are generally associated with earlier onset and more severe hearing impairment than are deletions, which suggests that the phenotypic differences may be caused by distinct mechanisms of pathogenesis. The two deletions that have been identified so far truncate the protein before the first transmembrane domain ${ }^{[54,55]}$, and hence, they can cause an expected reduction of $50 \%$ in channel activity. In contrast, missense mutations have been reported to exert a dominant-negative effect on wild type function that cause a higher reduction in channel $\operatorname{activity}^{[52,56]}$. Interestingly, most of the missense mutations occur within the P-loop domain in the pore region of the KCNQ4 channel ${ }^{[52,54,57-60]}$. The mechanism that underlies the effect of dominant-inhibition has not yet been identified. The first study to identify a trafficking-dependent dominant mechanism for the loss of KCNQ4 channel function in DFNA2 was in a novel mutation c.886G >A, which leads to the p.G296S substitution in the pore region of the KCNQ4 channel. Expression and functional studies that are conducted in Xenopus oocytes and transfected NIH-3T3 cells reveal that the G296S mutant exerts a strong dominant-negative effect on wild type channel activity by causing a defect in trafficking of KCNQ4 channels to the cell surface membrane.

Using pre- and postsynaptic recordings combined with immunohistochemistry, the recent research has found that KCNQ5 channels with unusually negative activation voltages are expressed in the calyx of Held, which is presynaptic of the medial nucleus of the trapezoid body (MNTB $)^{[11,61]}$. Given this voltage dependence, these channels account for most resting outward ionic current and determined presynaptic resting conductance and release probability. KCNQ5 has received relatively little attention so far because it is not associated with muscarinic signaling and has not yet been identified as the basis for channelopathies ${ }^{[37,62,63]}$. Nevertheless, similar to KCNQ4, its prominence in the auditory system suggests that it confers a particular advantage in maintaining high frequency synaptic signaling. This is congruent with the several molecular and biophysical specializations for preserving the timing of electrical signals that are associated with sound ${ }^{[64]}$.

\section{KCNQ channels in vision}

The retinal pigment epithelium (RPE) has a variety of functions that are critical to the integrity of the adjacent photoreceptors, including the phagocytosis of outer segments, the regeneration of photopigment, and the supply of nutrients and removal of waste ${ }^{[65]}$. In addition, the RPE helps control the volume and ionic composition of fluid in the subretinal space, the extracellular compartment that is bound by the photoreceptor outer segments and the apical aspects of the RPE and Müller (radial glial) cells ${ }^{[66]}$. Photoreceptor function critically depends upon the maintenance of subretinal $\mathrm{K}^{+}$concentration within narrow limits, which is achieved by $\mathrm{K}^{+}$transport mechanisms in the RPE and Müller cells. KCNQ mRNA and protein expression research has found that although KCNQ1, KCNQ4, and KCNQ5 transcripts are expressed in primate RPE, both KCNQ4 and KCNQ5 proteins are expressed in the monkey neural retina and in the RPE, while only KCNQ5 is expressed at a detectable level ${ }^{[67]}$. Using patch-clamp electrophysiology, research has investigated the pharmacological sensitivity of the M-type current in isolated monkey RPE cells to elucidate the subunit composition of the channel and found that the M-type current in monkey RPE is likely mediated by channels that are encoded by KCNQ4 and KCNQ5 subunits ${ }^{[68]}$. Mutations in KCNQ1 and KCNQ4 genes underlie a number of inherited diseases in humans, including cardiac arrhythmia and nonsyndromal deafness ${ }^{[4]}$; however, no disease has been linked to mutations of KCNQ5. Interestingly, no visual disorder has been linked to KCNQ1 or KCNQ4 mutations that cause channelopathies in other tissues. This suggests that if they are expressed, KCNQ1 and KCNQ4 subunits likely have minor or redundant roles in RPE and neural retina physiology. Nevertheless, to date, KCNQ5 mutations are not known to be associated with human disease.

\section{KCNQ channels in pain and touch sensation}

Painful stimulation of the skin and viscera is detected by thinly myelinated A- and unmyelinated C-fibers. These first order neurons, with cell bodies that are located in the dorsal root ganglia (DRG), transmit painful stimuli to the substantia gelatinosa of the dorsal horn via the dorsal roots. Second order neurons in the lateral spinothalamic tracts convey impulses that are associated with pain up to the nuclei of the ventroposterior thalamus (ventroposterior medial nucleus, VPM, and ventroposterior lateral nucleus, VPL), where painful impulses are integrated. From the thalamus, third order neurons convey impulses up to the cerebral cortex, where subjective interpretation of pain is thought to occur. Molecular and electrophysiological techniques have provided evidence 
for the expression of Kv7.2, 7.3 and 7.5 channels and functional Kv7.x based M-currents in the peripheral terminals, cell bodies, axons, and central terminals of sensory nerves ${ }^{[69-71]}$. Activation of the peripheral KCNQ channels suffices to relieve inflammatory pain ${ }^{[72]}$. KCNQ channels are also expressed in the dorsal horn of the spinal cord, and at key sites in the brain, such as the thalamus and cortex ${ }^{[69-71]}$. Collectively, these data show that functional Kv7.x channels are expressed at all levels of the pain pathway and that these channels may represent excellent targets for the treatment of various pain states ${ }^{[7]}$.

Behavioral studies with KCNQ modulators, most of which are used in target validation studies and include retigabine (N-(2-amino-4-[fluorobenzylamino]-phenyl)carbamic acid; D-23129 $)^{[13,74]}$ and flupirtine(N-[2-amino-6-[(4-fluorophenyl) methylamino]pyridin-3-yl]-carbamate $)^{[75-77]}$, have also provided evidence to indicate that KCNQ channels may represent valid targets for novel analgesic, anti-hyperalgesic and antiallodynic agents. In addition, an update concerning pre-clinical KCNQ drug discovery efforts will be expected, along with a summary of ongoing clinical trials with KCNQ channel.

KCNQ4 also presents in sensory neurons of the DRG, while in the periphery, $\mathrm{KCNQ} 4$ channels are expressed in lanceolate endings and circular nerve fibers of hair follicles and in Meissner bodies, at sites where they can modulate stimulus-excitation coupling. The electrophysiological recordings from single afferents from $\mathrm{Kcnq4}^{-/-}$mice and mice that carry a KCNQ4 mutation that are found in DFNA2-type monogenic dominant human hearing loss showed an elevated mechanosensitivity and an altered frequency response during rapid adaptation. Human subjects from independent DFNA2 pedigrees outperformed age-matched control subjects when tested for vibrotactile acuity at low frequencies ${ }^{[9]}$.

\section{KCNQ channels in olfactory sensation}

The accessory olfactory bulb (AOB) is the first central nervous system (CNS) relay for processing pheromonal sensory information ${ }^{[78]}$. It is an attractive region for study because of its simple structure, the observation that it consists of only three types of neurons (ie, one glutamate neuron (mitral cells) and two GABA neurons (granule cells and periglomerular cells)), and their implicated functions, such as information integration $^{[79,80]}$ or memory storage ${ }^{[81]}$. Muscarinic receptor mRNAs are expressed in the AOB (strong M1 and M4 and weak M3). The cholinergic action increases spontaneous mIPSCs in the olfactory bulb ${ }^{[82,83]}$. The KCNQ channel is a potassium channel that is closed by muscarinic activity ${ }^{[2]}$. Potassium channel closure excites the neuron by depolarizing its membrane as well as by making the membrane more susceptible to depolarizing inputs. Cholinergic modulation of spontaneous GABAergic currents (mIPSC) using whole-cell patch methods in AOB slices found that carbachol administration produced an increase in mIPSC frequency in mitral cells, but did not affect the responses of mitral cells to GABA that persists in the presence of combined glutamatergic receptor antagonists ${ }^{[84]}$. The carbachol effect was reduced by the muscarinic receptor M1 and M4 antagonist pirenzepine, but not by the M2 and M4 antagonist himbacine. The $\mathrm{KCNQ} / \mathrm{Kv} 7$ potassium channel openers retigabine and diclofenac blocked the carbachol action, while the KCNQ potassium channel blocker XE-911 increased mIPSC frequency, thereby suggesting that carbachol acts via the down-regulation of KCNQ channels to increase transmitter release ${ }^{[85]}$. Furthermore, the relationship between muscarinic stimulation and KCNQ channel down-regulation is well-established ${ }^{[2]}$. It is therefore probable that carbachol down-regulates the activity of KCNQ channels in granule cells dendrites and, through increased membrane depolarization, increases the open probability of membrane calcium channels, thereby resulting in an increase in synaptic vesicle release.

\section{KCNQ channels in learning and memory}

The activation of hippocampal $\mathrm{mAChR}$ by synaptically released acetylcholine facilitates the induction of synaptic plasticity and enhances cognitive function. The M1 subtype of $\mathrm{mAChR}$ is a prime candidate for mediating these cholinergic effects due to its ubiquitous expression in the cortex and hippocampus. Learning, working memory and induction of synaptic plasticity are all impaired in M1 receptor knockout mice $^{[86-88]}$. Furthermore, M1 mAChR specific agonists facilitate LTP induction ${ }^{[89-91]}$ and improve cognitive function in animal models ${ }^{[22]}$. M1 mAChR that are expressed on CA1 pyramidal cells inhibit both small conductance $\mathrm{Ca}^{2+}$-activated $\mathrm{K}_{\mathrm{Ca}}$ potassium channels (also known as SK channels) ${ }^{[91,93]}$ and voltageactivated Kv7 potassium channels ${ }^{[1,94,95]}$. The inhibition of $\mathrm{K}_{\mathrm{Ca}}$ channels facilitates long-term potentiation (LTP) by enhancing $\mathrm{Ca}^{2+}$ influx through postsynaptic NMDA receptors (NMDAR) ${ }^{[96]}$. The inhibition of KCNQ channels is also reported to facilitate LTP $^{[97,98]}$. KCNQ channel inhibition promotes NMDAR opening during LTP induction by enhancing depolarization during and after bursts of postsynaptic action potentials.

Activity-dependent depression of the spike ADP generates long-lasting intrinsic plasticity in hippocampal CA3 pyramidal neurons. XE991 both enhanced the ADP and completely eliminated its conditioning-induced depression ${ }^{[99]}$. XE991 also enhances learning and memory in healthy mice and reverts the cognitive impairment that is associated with acetylcholine depletion and neurodegeneration that is induced by kainic acid. Furthermore, behavioral training sessions regulate the M-current by transiently decreasing levels of KCNQ3 protein ${ }^{[97]}$. This effect may be achieved by altering basal hippocampal synaptic activity and by diminishing the stimulation threshold for long-term changes in synaptic efficacy and learning-related gene expression.

Mice that express a KCNQ2 subunit with a dominant-negative pore mutation that can suppress M-channel activity by coassembling with native KCNQ subunits developed epilepsy, behavioral hyperactivity, cognitive deficits, changes in brain morphology and markedly impaired hippocampus-dependent spatial memory in the Morris water maze, with signs of increased neuronal excitability, reduced spike-frequency adaptation, attenuated AHPs and reduced intrinsic subthreshold theta resonance ${ }^{[38]}$. The results support the notion that $\mathrm{M}$ channels are critical determinants of cellular and neuronal 
network excitability and that the attenuation of the $\mathrm{M}$ current has a profound effect on behavior and cognitive performance. Together, these results demonstrate that the inhibition of the M-current as a general strategy may be useful to enhance cognitive capacities in healthy and aging individuals as well as in those with neurodegenerative diseases.

\section{Future directions}

The identification of KCNQ channels and their relating channelopathies have been studied in recent decades. After 30 years of intense study, we have increased our knowledge of the physiological and pathological roles of KCNQ channels (Table 1). The potential therapeutic applications of Kv7 enhancers, as deduced from animal experimentation, have expanded from anti-nociceptive and anticonvulsant therapies to the treatment of migraine, anxiety, mania and addiction to psychostimulants ${ }^{[100]}$. Although Kv7/M-channel dysfunction may not have any role in such disorders, the widespread distribution of these channels provides a means of general treatment by reducing overall neural excitability when Kv7 channel activity is enhanced ${ }^{[37]}$. In the future, several questions will need to be resolved regarding the physiological assembly of KCNQ channels and their functional implications in complex neural circuits. First, we still lack sufficiently selective inhibitors and activators among the KCNQ family members. Although retigabine was approved for the treatment of epilepsy and XE991 has been widely used as a pharmacological tool, the selectivity of these drugs are still limited at the subtype level. Without a crystal structure of the KCNQ channel available, medium and high throughput screening with the aid of computer-based drug design are essential to exploit the versatility of drug-channel interactions. Second, the in vivo physiological assemble and functional localization of KCNQ channels requires further evidence. Although in vitro heteromultimers KCNQ2 and KCNQ3 could assemble into $\mathrm{M}$ currents, we still lack enough tools to exploit the integrative assembling of KCNQ4 and KCNQ5 and their accessory partners. Based upon current research regarding the multiple physiological and pathological roles of the KCNQ channel, the development of additional pharmacological models such as seizure, stroke, pain and mental illness, combined with the development of drug targets for KCNQ channels, will enhance our knowledge of KCNQ channel and provide general therapeutic prospects of relating channelopathies.

\section{Acknowledgements}

This work was supported in part by the National Natural Science Foundation of China (31128009, 31171011, 31171066 and 91413122) and the Ministry of Science and Technology of China (2013CB910601).

\section{References}

1 Brown DA, Adams PR. Muscarinic suppression of a novel voltagesensitive $\mathrm{K}^{+}$current in a vertebrate neurone. Nature 1980; 283 : 673-6.

2 Delmas P, Brown DA. Pathways modulating neural KCNQ/M (Kv7) potassium channels. Nat Rev Neurosci 2005; 6: 850-62.

3 Tyson J, Tranebjaerg L, McEntagart M, Larsen LA, Christiansen M, Whiteford ML, et al. Mutational spectrum in the cardioauditory syndrome of Jervell and Lange-Nielsen. Hum Genet 2000; 107: 499503.

4 Robbins J. KCNQ potassium channels: physiology, pathophysiology, and pharmacology. Pharmacol Ther 2001; 90: 1-19.

5 Wang HS, Pan Z, Shi W, Brown BS, Wymore RS, Cohen IS, et al. KCNQ2 and KCNQ3 potassium channel subunits: molecular correlates of the M-channel. Science 1998; 282: 1890-3.

6 Biervert C, Schroeder BC, Kubisch C, Berkovic SF, Propping P, Jentsch $\mathrm{TJ}$, et al. A potassium channel mutation in neonatal human epilepsy. Science 1998; 279: 403-6.

Table 1. Physiological roles and relating channelopathies of KCNQ subunits.

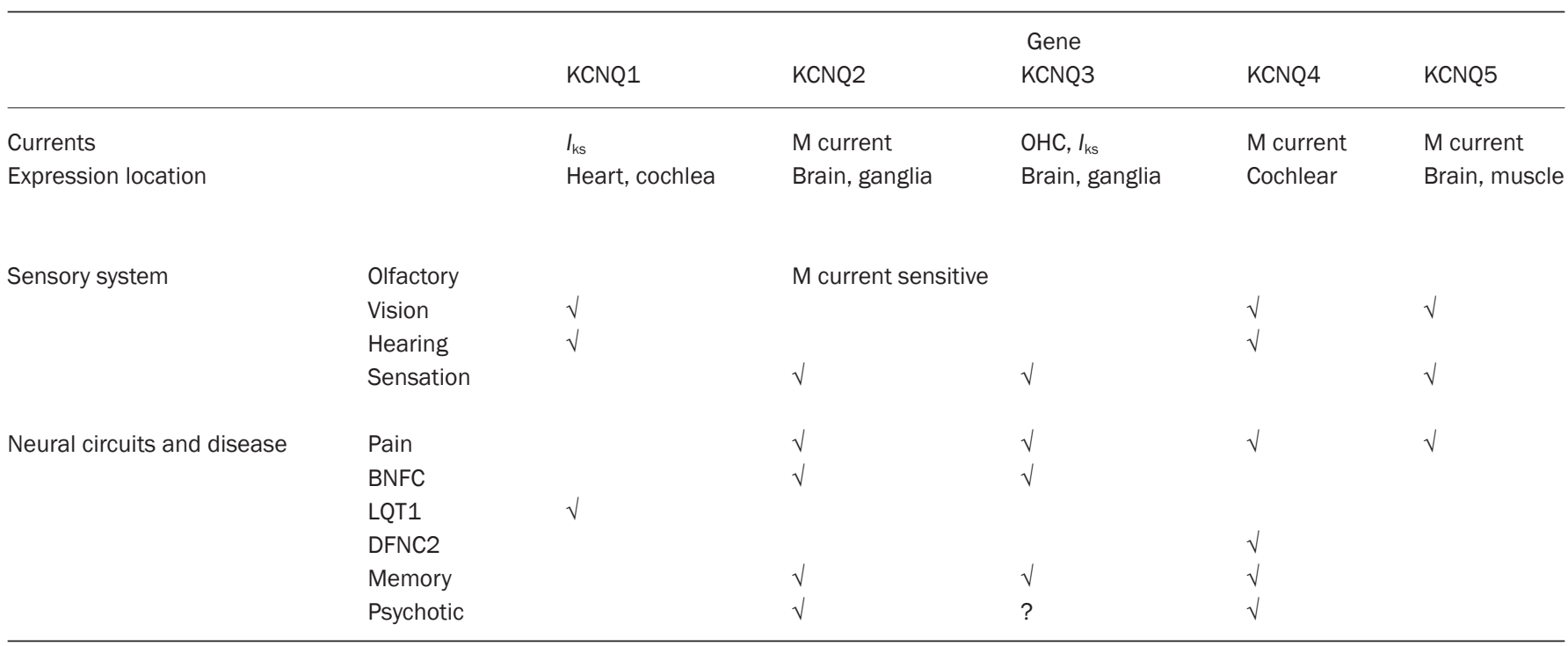


7 Charlier C, Singh NA, Ryan SG, Lewis TB, Reus BE, Leach RJ, et al. A pore mutation in a novel KQT-like potassium channel gene in an idiopathic epilepsy family. Nat Genet 1998; 18: 53-5.

8 Kharkovets T, Hardelin JP, Safieddine S, Schweizer M, El-Amraoui A, Petit $\mathrm{C}$, et al. KCNQ4, a $\mathrm{K}^{+}$channel mutated in a form of dominant deafness, is expressed in the inner ear and the central auditory pathway. Proc Natl Acad Sci U S A 2000; 97: 4333-8.

9 Heidenreich M, Lechner SG, Vardanyan V, Wetzel C, Cremers CW, De Leenheer EM, et al. KCNQ4 $\mathrm{K}^{+}$channels tune mechanoreceptors for normal touch sensation in mouse and man. Nat Neurosci 2012; 15 : 138-45.

10 Smith JS, lannotti CA, Dargis P, Christian EP, Aiyar J. Differential expression of kcnq2 splice variants: implications to $m$ current function during neuronal development. J Neurosci 2001; 21: 1096-103.

11 Huang H, Trussell LO. KCNQ5 channels control resting properties and release probability of a synapse. Nat Neurosci 2011; 14: 840-7.

12 Wang M, Gamo NJ, Yang Y, Jin LE, Wang XJ, Laubach M, et al. Neuronal basis of age-related working memory decline. Nature 2011; 476: 210-3.

13 Passmore GM, Selyanko AA, Mistry M, Al-Qatari M, Marsh SJ, Matthews $\mathrm{EA}$, et al. KCNQ/M currents in sensory neurons: significance for pain therapy. J Neurosci 2003; 23: 7227-36.

14 Zhang H, Craciun LC, Mirshahi T, Rohacs T, Lopes CM, Jin T, et al. $\mathrm{PIP}(2)$ activates KCNQ channels, and its hydrolysis underlies receptor-mediated inhibition of M currents. Neuron 2003; 37: 963-75.

15 Li Y, Gamper N, Hilgemann DW, Shapiro MS. Regulation of Kv7 (KCNQ) $\mathrm{K}^{+}$channel open probability by phosphatidylinositol 4,5-bisphosphate. J Neurosci 2005; 25: 9825-35.

16 Zaika O, Lara LS, Gamper N, Hilgemann DW, Jaffe DB, Shapiro MS. Angiotensin II regulates neuronal excitability via phosphatidylinositol 4,5-bisphosphate-dependent modulation of Kv7 (M-type) $\mathrm{K}^{+}$channels. J Physiol 2006; 575: 49-67.

17 Bofill-Cardona E, Vartian N, Nanoff C, Freissmuth M, Boehm S. Two different signaling mechanisms involved in the excitation of rat sympathetic neurons by uridine nucleotides. Mol Pharmacol 2000; 57 : 1165-72.

18 Delmas P, Wanaverbecq N, Abogadie FC, Mistry M, Brown DA. Signaling microdomains define the specificity of receptor-mediated InsP(3) pathways in neurons. Neuron 2002; 34: 209-20.

19 Zaika O, Tolstykh GP, Jaffe DB, Shapiro MS. Inositol triphosphatemediated $\mathrm{Ca}^{2+}$ signals direct purinergic $\mathrm{P} 2 \mathrm{Y}$ receptor regulation of neuronal ion channels. J Neurosci 2007; 27: 8914-26.

20 Gamper N, Shapiro MS. Calmodulin mediates $\mathrm{Ca}^{2+}$-dependent modulation of M-type $K^{+}$channels. J Gen Physiol 2003; 122: 17-31.

21 Gamper N, Li Y, Shapiro MS. Structural requirements for differential sensitivity of KCNQ $\mathrm{K}^{+}$channels to modulation by $\mathrm{Ca}^{2+} /$ calmodulin. Mol Biol Cell 2005; 16: 3538-51.

22 Gamper N, Shapiro MS. Regulation of ion transport proteins by membrane phosphoinositides. Nat Rev Neurosci 2007; 8: 921-34.

23 Gamper N, Shapiro MS. Target-specific PIP(2) signalling: how might it work? J Physiol 2007; 582: 967-75.

24 Lopes CM, Remon JI, Matavel A, Sui JL, Keselman I, Medei E, et al. Protein kinase A modulates PLC-dependent regulation and PIP2sensitivity of $\mathrm{K}^{+}$channels. Channels (Austin) 2007; 1: 124-34.

25 Wen H, Jurkovicova D, Pickel VM, Gioio AE, Kaplan BB. Identification of a novel membrane-associated protein expressed in neurons of the squid and rodent nervous systems. Neuroscience 2002; 114: 995-1004.

26 Hernandez CC, Zaika O, Tolstykh GP, Shapiro MS. Regulation of neural KCNQ channels: signalling pathways, structural motifs and functional implications. J Physiol 2008; 586: 1811-21.
27 Hoshi N, Zhang JS, Omaki M, Takeuchi T, Yokoyama S, Wanaverbecq $\mathrm{N}$, et al. AKAP150 signaling complex promotes suppression of the Mcurrent by muscarinic agonists. Nat Neurosci 2003; 6: 564-71.

28 Li Y, Langlais P, Gamper N, Liu F, Shapiro MS. Dual phosphorylations underlie modulation of unitary KCNQ $\mathrm{K}^{+}$channels by Src tyrosine kinase. J Biol Chem 2004; 279: 45399-407.

29 Li Y, Gamper N, Shapiro MS. Single-channel analysis of KCNQ K+ channels reveals the mechanism of augmentation by a cysteinemodifying reagent. J Neurosci 2004; 24: 5079-90.

30 Zhang Q, Zhou P, Chen Z, Li M, Jiang H, Gao Z, et al. Dynamic PIP2 interactions with voltage sensor elements contribute to KCNQ2 channel gating. Proc Natl Acad Sci U S A 2013; 110: 20093-8.

31 Chen L, Zhang Q, Qiu Y, Li Z, Chen Z, Jiang H, et al. Migration of PIP2 lipids on voltage-gated potassium channel surface influences channel deactivation. Sci Rep 2015; 5: 15079.

32 Zhang J, Shapiro MS. Activity-dependent transcriptional regulation of M-Type (Kv7) K ${ }^{+}$channels by AKAP79/150-mediated NFAT actions. Neuron 2012; 76: 1133-46.

33 Storm JF. Action potential repolarization and a fast after-hyperpolarization in rat hippocampal pyramidal cells. J Physiol 1987; 385: 73359.

34 Williams SR, Stuart GJ. Mechanisms and consequences of action potential burst firing in rat neocortical pyramidal neurons. J Physiol 1999; 521 Pt 2: 467-82.

35 Bean BP. The action potential in mammalian central neurons. Nat Rev Neurosci 2007; 8: 451-65.

36 Piccinin S, Randall AD, Brown JT. KCNQ/Kv7 channel regulation of hippocampal gamma-frequency firing in the absence of synaptic transmission. J Neurophysiol 2006; 95: 3105-12.

37 Brown DA, Passmore GM. Neural KCNQ (Kv7) channels. Br J Pharmacol 2009; 156: 1185-95.

38 Peters HC, Hu H, Pongs O, Storm JF, Isbrandt D. Conditional transgenic suppression of $\mathrm{M}$ channels in mouse brain reveals functions in neuronal excitability, resonance and behavior. Nat Neurosci 2005; 8: 51-60.

39 Luebke Jl, Chang YM. Effects of aging on the electrophysiological properties of layer 5 pyramidal cells in the monkey prefrontal cortex. Neuroscience 2007; 150: 556-62.

40 Goldman-Rakic PS. Cellular basis of working memory. Neuron 1995; 14: 477-85.

41 Dodson PD, Forsythe ID. Presynaptic $\mathrm{K}^{+}$channels: electrifying regulators of synaptic terminal excitability. Trends Neurosci 2004; 27 : 210-7.

$42 \mathrm{Kim} \mathrm{JH}$, Sizov I, Dobretsov M, von Gersdorff H. Presynaptic $\mathrm{Ca}^{2+}$ buffers control the strength of a fast post-tetanic hyperpolarization mediated by the alpha3 $\mathrm{Na}^{+} / \mathrm{K}^{+}$-ATPase. Nat Neurosci 2007; 10 : 196-205.

43 Huang H, Trussell LO. Control of presynaptic function by a persistent $\mathrm{Na}^{+}$current. Neuron 2008; 60: 975-9.

44 Gardiner M, Lehesjoki AE. Genetics of the epilepsies. Curr Opin Neurol 2000; 13: 157-64.

45 Ronen GM, Rosales TO, Connolly M, Anderson VE, Leppert M. Seizure characteristics in chromosome 20 benign familial neonatal convulsions. Neurology 1993; 43: 1355-60.

46 Singh NA, Charlier C, Stauffer D, DuPont BR, Leach RJ, Melis R, et al. A novel potassium channel gene, KCNQ2, is mutated in an inherited epilepsy of newborns. Nat Genet 1998; 18: 25-9.

47 Hirose S, Zenri F, Akiyoshi H, Fukuma G, Iwata H, Inoue T, et al. A novel mutation of KCNQ3 (c.925T-->C) in a Japanese family with benign familial neonatal convulsions. Ann Neurol 2000; 47: 822-6.

48 Schroeder BC, Kubisch C, Stein V, Jentsch TJ. Moderate loss of func- 
tion of cyclic-AMP-modulated KCNQ2/KCNQ3 $\mathrm{K}^{+}$channels causes epilepsy. Nature 1998; 396: 687-90.

49 Neyroud N, Tesson F, Denjoy I, Leibovici M, Donger C, Barhanin J, et al. A novel mutation in the potassium channel gene KVLQT1 causes the Jervell and Lange-Nielsen cardioauditory syndrome. Nat Genet 1997; 15: 186-9.

50 Schmitt N, Schwarz M, Peretz A, Abitbol I, Attali B, Pongs O. A recessive C-terminal Jervell and Lange-Nielsen mutation of the KCNQ1 channel impairs subunit assembly. EMBO J 2000; 19: 332-40.

51 Splawski I, Timothy KW, Vincent GM, Atkinson DL, Keating MT. Molecular basis of the long-QT syndrome associated with deafness. N Engl J Med 1997; 336: 1562-7.

52 Kubisch C, Schroeder BC, Friedrich T, Lutjohann B, El-Amraoui A, Marlin S, et al. KCNQ4, a novel potassium channel expressed in sensory outer hair cells, is mutated in dominant deafness. Cell 1999; 96: 437-46.

53 Kharkovets T, Dedek K, Maier H, Schweizer M, Khimich D, Nouvian $\mathrm{R}$, et al. Mice with altered KCNQ4 $\mathrm{K}^{+}$channels implicate sensory outer hair cells in human progressive deafness. EMBO J 2006; 25: 642-52.

54 Coucke PJ, Van Hauwe P, Kelley PM, Kunst H, Schatteman I, Van Velzen D, et al. Mutations in the KCNQ4 gene are responsible for autosomal dominant deafness in four DFNA2 families. Hum Mol Genet 1999; 8: 1321-8.

55 Kamada F, Kure S, Kudo T, Suzuki Y, Oshima T, Ichinohe A, et al. A novel KCNQ4 one-base deletion in a large pedigree with hearing loss: implication for the genotype-phenotype correlation. J Hum Genet 2006; 51: 455-60.

56 Jentsch TJ. Neuronal KCNQ potassium channels: physiology and role in disease. Nat Rev Neurosci 2000; 1: 21-30.

57 Talebizadeh Z, Kelley PM, Askew JW, Beisel KW, Smith SD. Novel mutation in the KCNQ4 gene in a large kindred with dominant progressive hearing loss. Hum Mutat 1999; 14: 493-501.

58 Akita J, Abe S, Shinkawa H, Kimberling WJ, Usami S. Clinical and genetic features of nonsyndromic autosomal dominant sensorineural hearing loss: KCNQ4 is a gene responsible in Japanese. J Hum Genet 2001; 46: 355-61.

59 Van Camp G, Coucke PJ, Akita J, Fransen E, Abe S, De Leenheer EM, et al. A mutational hot spot in the KCNQ4 gene responsible for autosomal dominant hearing impairment. Hum Mutat 2002; 20: 15-9.

60 Mencia A, Gonzalez-Nieto D, Modamio-Hoybjor S, Etxeberria A, Aranguez G, Salvador N, et al. A novel KCNQ4 pore-region mutation (p.G296S) causes deafness by impairing cell-surface channel expression. Hum Genet 2008; 123: 41-53.

61 Garcia-Pino E, Caminos E, Juiz JM. KCNQ5 reaches synaptic endings in the auditory brainstem at hearing onset and targeting maintenance is activity-dependent. J Comp Neurol 2010; 518: 1301-14.

62 Schroeder BC, Hechenberger M, Weinreich F, Kubisch C, Jentsch TJ. KCNQ5, a novel potassium channel broadly expressed in brain, mediates M-type currents. J Biol Chem 2000; 275: 24089-95.

63 Lerche C, Scherer CR, Seebohm G, Derst C, Wei AD, Busch AE, et al. Molecular cloning and functional expression of KCNQ5, a potassium channel subunit that may contribute to neuronal M-current diversity. J Biol Chem 2000; 275: 22395-400.

64 Trussell LO. Synaptic mechanisms for coding timing in auditory neurons. Annu Rev Physiol 1999; 61: 477-96.

65 Strauss 0. The retinal pigment epithelium in visual function. Physiol Rev 2005; 85: 845-81.

66 Quinn RH, Miller SS. Ion transport mechanisms in native human retinal pigment epithelium. Invest Ophthalmol Vis Sci 1992; 33: 3513-27.
67 Zhang X, Yang D, Hughes BA. KCNQ5/K(v)7.5 potassium channel expression and subcellular localization in primate retinal pigment epithelium and neural retina. Am J Physiol Cell Physiol 2011; 301: C1017-26.

68 Pattnaik BR, Hughes BA. Effects of KCNQ channel modulators on the M-type potassium current in primate retinal pigment epithelium. Am J Physiol Cell Physiol 2012; 302: C821-33.

69 Wickenden AD, McNaughton-Smith G. Kv7 channels as targets for the treatment of pain. Curr Pharm Des 2009; 15: 1773-98.

70 Rigdon RO. Protocols for the prevention of intravascular devicerelated infections. Crit Care Nurs Q 2001; 24: 39-47.

71 Devaux JJ, Kleopa KA, Cooper EC, Scherer SS. KCNQ2 is a nodal K channel. J Neurosci 2004; 24: 1236-44.

72 Zheng Y, Xu H, Zhan L, Zhou X, Chen X, Gao Z. Activation of peripheral KCNQ channels relieves gout pain. Pain 2015; 156: 1025-35.

73 Rivera-Arconada I, Martinez-Gomez J, Lopez-Garcia JA. M-current modulators alter rat spinal nociceptive transmission: an electrophysiological study in vitro. Neuropharmacology 2004; 46: 598-606.

74 Dost R, Rostock A, Rundfeldt C. The anti-hyperalgesic activity of retigabine is mediated by KCNQ potassium channel activation. Naunyn Schmiedebergs Arch Pharmacol 2004; 369: 382-90.

75 Szelenyi I, Nickel B, Borbe HO, Brune K. Mode of antinociceptive action of flupirtine in the rat. Br J Pharmacol 1989; 97: 835-42.

76 Swedberg MD. The mouse grid-shock analgesia test: pharmacological characterization of latency to vocalization threshold as an index of antinociception. J Pharmacol Exp Ther 1994; 269: 1021-8.

77 Diamantis W, Gordon R, Sofia RD. Analgesic activity following combined oral administration of flupirtine maleate and peripherally acting analgesics in mice and rats. Postgrad Med J 1987; 63 Suppl 3: 29-34.

78 Luo M, Fee MS, Katz LC. Encoding pheromonal signals in the accessory olfactory bulb of behaving mice. Science 2003; 299: 1196201.

79 Xu F, Schaefer M, Kida I, Schafer J, Liu N, Rothman DL, et al. Simultaneous activation of mouse main and accessory olfactory bulbs by odors or pheromones. J Comp Neurol 2005; 489: 491-500.

80 Hendrickson RC, Krauthamer S, Essenberg JM, Holy TE. Inhibition shapes sex selectivity in the mouse accessory olfactory bulb. J Neurosci 2008; 28: 12523-34.

81 Kaba H, Hayashi Y, Higuchi T, Nakanishi S. Induction of an olfactory memory by the activation of a metabotropic glutamate receptor. Science 1994; 265: 262-4.

82 Castillo PE, Carleton A, Vincent JD, Lledo PM. Multiple and opposing roles of cholinergic transmission in the main olfactory bulb. J Neurosci 1999; 19: 9180-91.

83 Ghatpande AS, Sivaraaman K, Vijayaraghavan S. Store calcium mediates cholinergic effects on mIPSCs in the rat main olfactory bulb. J Neurophysiol 2006; 95: 1345-55.

84 Takahashi Y, Kaba H. Muscarinic receptor type 1 (M1) stimulation, probably through $\mathrm{KCNQ} / \mathrm{Kv} 7$ channel closure, increases spontaneous GABA release at the dendrodendritic synapse in the mouse accessory olfactory bulb. Brain Res 2010; 1339: 26-40.

85 Martire M, Castaldo P, D'Amico M, Preziosi P, Annunziato L, Taglialatela M. M channels containing KCNQ2 subunits modulate norepinephrine, aspartate, and GABA release from hippocampal nerve terminals. J Neurosci 2004; 24: 592-7.

86 Shinoe T, Matsui M, Taketo MM, Manabe T. Modulation of synaptic plasticity by physiological activation of M1 muscarinic acetylcholine receptors in the mouse hippocampus. J Neurosci 2005; 25: 11194200.

87 Anagnostaras SG, Murphy GG, Hamilton SE, Mitchell SL, Rahnama 
NP, Nathanson NM, et al. Selective cognitive dysfunction in acetylcholine M1 muscarinic receptor mutant mice. Nat Neurosci 2003; 6: 51-8.

88 Wess J. Muscarinic acetylcholine receptor knockout mice: novel phenotypes and clinical implications. Annu Rev Pharmacol Toxicol 2004; 44: 423-50.

89 Seol GH, Ziburkus J, Huang S, Song L, Kim IT, Takamiya K, et al. Neuromodulators control the polarity of spike-timing-dependent synaptic plasticity. Neuron 2007; 55: 919-29.

90 Boddeke EW, Enz A, Shapiro G. SDZ ENS 163, a selective muscarinic M1 receptor agonist, facilitates the induction of long-term potentiation in rat hippocampal slices. Eur J Pharmacol 1992; 222: 21-5.

91 Buchanan KA, Petrovic MM, Chamberlain SE, Marrion NV, Mellor JR. Facilitation of long-term potentiation by muscarinic $\mathrm{M}(1)$ receptors is mediated by inhibition of SK channels. Neuron 2010; 68: 948-63.

92 Dean B, Bymaster FP, Scarr E. Muscarinic receptors in schizophrenia. Curr Mol Med 2003; 3: 419-26.

93 Giessel AJ, Sabatini BL. M1 muscarinic receptors boost synaptic potentials and calcium influx in dendritic spines by inhibiting postsynaptic SK channels. Neuron 2010; 68: 936-47.

94 Madison DV, Lancaster B, Nicoll RA. Voltage clamp analysis of cho- linergic action in the hippocampus. J Neurosci 1987; 7: 733-41.

95 Marrion NV, Smart TG, Marsh SJ, Brown DA. Muscarinic suppression of the M-current in the rat sympathetic ganglion is mediated by receptors of the M1-subtype. Br J Pharmacol 1989; 98: 557-73.

96 Ngo-Anh TJ, Bloodgood BL, Lin M, Sabatini BL, Maylie J, Adelman JP. SK channels and NMDA receptors form a $\mathrm{Ca}^{2+}$-mediated feedback loop in dendritic spines. Nat Neurosci 2005; 8: 642-9.

97 Fontan-Lozano A, Suarez-Pereira I, Delgado-Garcia JM, Carrion AM. The M-current inhibitor XE991 decreases the stimulation threshold for long-term synaptic plasticity in healthy mice and in models of cognitive disease. Hippocampus 2011; 21: 22-32.

98 Lampe BJ, Gaskill JL, Keim SC, Brown BS. Linopirdine reduces stimulus intensity threshold for induction of long-term potentiation in the Schaffer collateral/CA1 pathway in rat hippocampal slices. Neurosci Lett 1997; 222: 135-7.

99 Brown JT, Randall AD. Activity-dependent depression of the spike after-depolarization generates long-lasting intrinsic plasticity in hippocampal CA3 pyramidal neurons. J Physiol 2009; 587: 1265-81.

100 Grunnet M, Strobaek D, Hougaard C, Christophersen P. Kv7 channels as targets for anti-epileptic and psychiatric drug-development. Eur J Pharmacol 2014; 726: 133-7. 